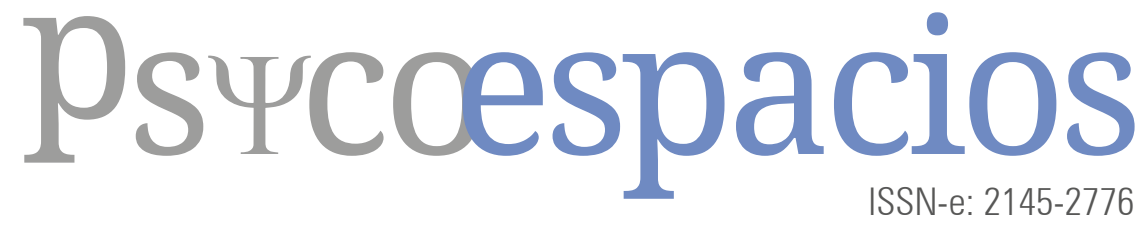

Vol. 15, № 26, enero-junio 2021 


\title{
La escuela y la migración: experiencias de niños venezolanos en Colombia
}

\author{
School and migration: \\ experiences of Venezuelan children in Colombia
}

\author{
Katy Luz Millán OTero ${ }^{\mathrm{a}}$ \\ Universidad Católica Luis Amigó, Colombia \\ https://orcid.org/0000-0002-8895-7098 \\ Nicolasa María Duran Palacio \\ Universidad Católica Luis Amigó, Colombia \\ https://orcid.org/O000-0001-5492-6931 \\ Laura Andrea Rodríguez Marín \\ Universidad Católica Luis Amigó, Colombia \\ https://orcid.org/0000-0003-4123-7058 \\ Andrea García Hincapié \\ Universidad Católica Luis Amigó, Colombia \\ https://orcid.org/0000-0001-5760-468X
}

aAutor de correspondencia: katy.millanot@amigo.edu.co

Recibido: 26 mayo 2021 Aceptado: 23 agosto 2021 Publicado: 24 septiembre 2021

Cómo citar este artículo: Millán Otero, k.L., Durán Palacio, N. M., Rodríguez Marín, L.A. y Hincapié García,

A. (2021). La escuela y la migración: experiencias de niños venezolanos en Colombia. Psicoespacios, 15(26). http///doi

\section{Resumen}

En los últimos años las transformaciones sociales, económicas y políticas de Venezuela han afectado la dinámica doméstica de la región y se han extrapolado más allá del continente, siendo la migración uno de sus efectos de mayor importancia histórica y coyuntural. El éxodo de los venezolanos hacia Colombia ha modificado no solamente la dinámica social del país de acogida, sino también las interacciones en las instituciones educativas, tras la incursión de niños y niñas migrantes. Esta investigación buscó analizar la experiencia de los niños venezolanos en las aulas de clase en la ciudad de Medellín. El horizonte de la investigación es cualitativo enmarcado en el método de estudio de caso que aporta descripciones densas con el propósito de interpretar y teorizar sobre la situación que es objeto de estudio. Se usó la entrevista 
semiestructurada y el mural de situaciones para la recolección de la información. Los hallazgos evidencian los desafíos que deben enfrentar los participantes en el nuevo país. En primer lugar, la xenofobia que por su condición de migrantes experimentan por parte de sus pares, quienes replican los estereotipos de los adultos exponiendo a los niños y niñas venezolanos a experiencias de "matoneo". En segundo lugar, las dificultades para adaptarse al currículo colombiano y finalmente los tipos de duelo migratorios que deben elaborar, principalmente el duelo a la familia y amigos, a la lengua, la tierra y la cultura. Se discute el papel de la escuela como facilitador del proceso de inclusión de los estudiantes extranjeros.

Palabras claves: migración, escuela, duelo migratorio, socialización secundaria, Venezuela.

\begin{abstract}
In recent years, Venezuela's social, economic and political transformations have affected the domestic dynamics of the region and have extrapolated beyond the continent, with migration being one of its most important historical and conjunctural effects. The exodus of Venezuelans to Colombia has modified not only the social dynamics of the host country, but also the interactions in educational institutions, following the incursion of migrant children. This research sought to analyze the experience of Venezuelan children in classrooms in the city of Medellin. The horizon of the research is qualitative framed in the case study method that provides dense descriptions with the purpose of interpreting and theorizing about the situation that is the object of study. The semi-structured interview and the situation mural were used to collect information. The findings show the challenges faced by the participants in the new country. In the first place, the xenophobia that they experience from their peers, who replicate the stereotypes of adults, exposing Venezuelan children to bullying. Secondly, the difficulties in adapting to the Colombian curriculum and finally, the types of migratory mourning that must be elaborated, mainly the mourning of family and friends, language, land and culture. The role of the school as a facilitator of the inclusion process of foreign students is discussed.
\end{abstract}

Keywords: migration, school, migratory grief, secondary socialization, Venezuela.

\section{Introducción}

La migración humana no es un fenómeno nuevo, pero ha cambiado significativamente en número y naturaleza con el crecimiento de la globalización, la facilidad del transporte y las comunicaciones internacionales, los efectos del cambio climático, los conflictos armados internos, entre otros (Zimmerman et al., 2011).

La Organización Internacional para las Migraciones (OIM, 2006) conceptualiza la migración como el desplazamiento de una población hacia otro Estado o dentro del mismo territorio. La decisión de la movilidad se puede dar de forma libre y voluntaria o, por el contrario, ser forzada por situaciones o personas que comprometen la integridad del sujeto en el país de origen. Aunque existen múltiples categorías en torno a la migración, en Colombia se toma el estatus de irregular y regular. El primero hace alusión a la situación de las personas que ingresan a un país sin el cumplimiento de los requisitos legales o que dejan de tener estatus legal debido al vencimiento de su visado. Por el contrario, el migrante regular es aquel que entra y permanece al país receptor por los canales legales y cumple con los requisitos nacionales para residir en el territorio (OIM, 2006).

Durante los siglos XIX y XX Venezuela fue un país receptor de inmigrantes, pero en las últimas décadas más de un millón quinientos venezolanos han emigrado al exterior. El patrón migratorio cambió "motivado por una crisis nacional que incluye un cambio en el 
modelo político, un desequilibrio económico que se ha ido incluso 'institucionalizando' durante los últimos años, y una descomposición social inédita para la historia de Venezuela" (Castillo Crasto y Reguant Álvarez, 2017, p. 13).

Si bien Colombia ha sido tradicionalmente un país expulsor de personas a causa del conflicto armado interno, ante la llegada masiva de venezolanos ha pasado a ser receptor. Aspectos como la cercanía geográfica, la relación histórica-cultural con Venezuela y la flexibilidad en la regulación migratoria han convertido a Colombia en uno de los principales destinos para migrar por parte de los venezolanos (Restrepo Pineda y Jaramillo Jaramillo, 2020).

Migración Colombia (Ministerio de Relaciones Exteriores de Colombia, 2021) reportó durante el 2020 el ingreso de 1729537 venezolanos, de estos 762823 son regulares y 966714 irregulares, ya sea porque superaron el tiempo de permanencia o porque ingresaron sin autorización. En el caso de los menores de edad, se estima que el $8 \%$ (274 683) del total de los migrantes corresponde a niños y niñas entre 5 a 17 años.

Bauman (2016) señala que en el mundo globalizado el otro diferente es un extraño que llama a la puerta y que se puede reducir a una condición inferior a los autóctonos que han sido relegados y confinados en el país. Estas diferencias traspasan los diferentes escenarios de la acción social, entre ellos el ambiente escolar. Ante los cambios globales, la escuela puede ser considerada ajena a los problemas del mundo exterior y los procesos de socialización que subjetivizan a los estudiantes (Bauman, 2013), por lo que puede parecer desacoplada a las condiciones que presenta la cultura.

No hay que olvidar que cuando los contextos sociales cambian de manera fundamental o inesperada los acontecimientos importantes, las instituciones sociales y la personalidad pueden informar la previsión de patrones futuros del curso de la vida, es decir, "los eventos históricos y los cambios económicos, demográficos, sociales y culturales moldean o configuran tanto las vidas individuales como los agregados poblacionales denominados cohortes o generaciones" (Blanco, 2011, p. 6). En este sentido, el curso de vida como perspectiva teórica permite comprender el impacto de la migración como proceso macrosocial en las trayectorias de la vida de los sujetos.

Uno de los principales espacios donde el niño migrante se va a desenvolver y va a ir adaptándose al proceso de migración es en la escuela; allí va a socializar con pares y personas adultas diferentes a su familia. Suárez-Orozco y Suárez-Orozco (2008) hablan de que la escuela cumple un rol fundamental en el proceso de integración de las niñas y los niños migrantes, porque se puede decir que ahí es donde pasan la mayor parte del tiempo, aprenden el idioma o las expresiones locales y las normas del lugar de destino, teniendo así la posibilidad de crear vínculos entre pares.

La socialización secundaria, según Berget y Luckman (1968), permite que los sujetos incorporen nuevos roles y se introduzcan a los contextos de su sociedad. El niño o adolescente lleva lo aprendido en el hogar a un nuevo espacio y lo une con los nuevos aprendizajes que reciba allí en el aula de clase. Uno de los aspectos que problematiza la socialización de los estudiantes extranjeros es la discriminación por parte de los nacionales, quienes expresan los discursos y prácticas que se arraigan en la sociedad. El espacio escolar puede reproducir, entonces, interacciones de dominación y diferenciación que expresan las desigualdades y vulneraciones de las que puede ser víctima un migrante (Joiko y Vásquez, 2016; Matus y Rojas, 2015; Pavez Soto, 2012a).

Cuando las niñas y los niños participan en procesos de movilidad familiar, la sociedad 
de destino utiliza variados y contradictorios criterios para construir y posicionarlos en la categoría sociológica de "inmigrantes". Al igual que ocurre con las personas adultas inmigrantes, las niñas y los niños se consideran culturalmente diferentes (alteridad) respecto de la sociedad anfitriona (homogénea supuestamente); y por haber participado en una socialización y educación en valores de las familias de origen inmigrante, se piensa que comparten los rasgos que les hacen diferentes (Pavez Soto, 2012a, p. 80).

La experiencia de socialización en el aula puede afectar y entorpecer la integración y la autoestima del estudiante migrante. Si es tratado de manera positiva el sujeto se siente dignificado y competente, lo que favorece la adaptación. Por el contrario, las respuestas ante las expresiones negativas pueden variar desde la construcción de una identidad desvalorizada o desarrollar resistencia a la escuela y los procesos de enseñanza aprendizaje (Suárez-Orozco y Suárez-Orozco, 2003).

La interseccionalidad coadyuva a explicar cómo la contribución única de un factor sociodemográfico, como ser extranjero, puede incidir en los vínculos con los otros. Es decir, las identidades interseccionales contornean las experiencias de vida en un contexto social particular (Kelly, 2011). En este sentido, la condición de ser venezolano de los niños puede circunscribir las relaciones con los otros en el contexto de llegada.

Por ejemplo, la incorporación de los niños al sistema educativo en el país de llegada puede estar mediada por obstáculos, que se destacan en la literatura y se asocian a las dificultades en la comprensión del idioma (López Castro, 1999), conflictos en la matrícula, la validación de sus estudios en el país de llegada y la adaptación a las diferencias culturales y curriculares del nuevo sistema educativo (Vargas Valle y Camacho Rojas, 2016; Cerón et al., 2017); "los bajos resultados académicos como las dificultades en los procesos de adaptación cultural contribuyen a ensanchar aún más las brechas y desigualdades en el plano escolar" (Jiménez et al., 2017, p. 106).

Achotegui (2010) considera que la migración confronta al sujeto a niveles de estrés que pueden superar su capacidad de adaptación; migrar supone diversas pérdidas significativas que enfrentan al sujeto con estresores que lo obligan a expandir sus recursos psicológicos adaptativos que están en el límite entre la salud mental y la enfermedad. Algunas de estas pérdidas son: duelo por la familia y amigos, por la lengua, la cultura, la tierra, el estatus social, contacto por el grupo étnico y riesgos para la integridad física (Millán Otero et al., 2021; Sánchez Mimbela, 2017).

Vera Noriega (2009) reseña diferencias entre los tipos de estresores y síntomas entre los niños y adultos migrantes. En el caso de los niños, ellos también elaboran el duelo tras la separación de sus antiguos apegos emocionales, la reconstrucción de la identidad ahora como migrante, la separación de su lugar de origen y la adaptación a la nueva cultura (Chiu et al., 1992). Los síntomas que se pueden evidenciar son un posible fracaso escolar y variación en las relaciones de apego.

Los flujos de movilidad humana en el mundo han supuesto grandes desafíos para el sistema educativo. Se hace necesario comprender la experiencia de los niños migrantes para pensar estrategias concretas relativas a su acogida en los espacios escolares. Esta investigación se realizó con el fin de analizar la experiencia de los niños migrantes venezolanos en la institución Educativa Álvaro Marín Velasco del municipio de Medellín, se focalizó el análisis en los procesos de socialización secundaria y la experiencia de duelo migratorio.

\section{Método}

La investigación se basó en el enfoque cualitativo; aquel que estudia la realidad en su contexto natural, observando cómo sucede, interpretando los fenómenos de acuerdo con 
las personas implicadas. Los datos emergieron a partir de las experiencias de los actores sociales (Taylor y Bogdan, 1989). Se empleó el estudio de caso como medio para analizar el fenómeno. El estudio de caso se asume como un sistema o fenómeno delimitado e integrado que ocurre en un contexto específico (Stake, 1999), y que aporta descripciones densas con el propósito de interpretar y teorizar sobre la situación que es objeto de estudio.

El espacio de la investigación fue la Institución Educativa Álvaro Marín Velasco, institución de carácter público, ubicada en la comuna Manrique en el extremo nororiental de la ciudad de Medellín. Las condiciones sociales de la población son de alta vulnerabilidad, en su mayoría desplazados. En el ámbito educativo algunas instituciones carecen de un tratamiento de contextualización con un enfoque poblacional incluyente y diferenciador (Ortiz Giraldo, 2012).

Las técnicas de recolección de información empleadas fueron la entrevista en dupla, que se realizó con los niños y las niñas, al igual que el mural de situaciones en la institución. En el caso de los docentes, se implementó la entrevista semiestructurada. La selección de los participantes se hizo de forma intencional a partir de la inmersión en campo. Como criterio de inclusión se estableció: que los niños y niñas fuesen de nacionalidad venezolana, estudiantes de básica primaria de la Institución Educativa Álvaro Marín Velasco y que sus padres autorizaran mediante la firma del consentimiento informado la participación de los menores de edad. En el caso de los docentes, el criterio para hacer parte del estudio fue que tuvieran interacción permanente en la institución con los niños y niñas, y aceptar la participación en la investigación.

Como se muestra en la tabla 1 , fueron en total 10 los estudiantes participantes (5 niños y 5 niñas), con edades entre 8 y 11 años de edad, de los años tercero, cuarto y quinto. Por parte del cuerpo docente se vincularon 3 adultos a la investigación.

Tabla 1. Descripción de los participantes de la investigación

\begin{tabular}{|c|c|c|c|c|c|}
\hline $\begin{array}{l}\text { Código del } \\
\text { participante }\end{array}$ & $\begin{array}{c}\text { Edad } \\
\text { en años }\end{array}$ & Género & Grado & $\begin{array}{l}\text { Tiempo de permanencia } \\
\text { en Colombia }\end{array}$ & $\begin{array}{l}\text { Tipo de } \\
\text { familia }\end{array}$ \\
\hline LD11FE & 11 & Femenino & 4to primaria & 2 meses de residencia & Extensa \\
\hline S8ME & 8 & Masculino & 4to primaria & 2 años & Nuclear \\
\hline A8ME & 8 & Masculino & 3ro primaria & 2 años & Nuclear \\
\hline Y9FE & 9 & Femenino & 3ro primaria & 1 año & Nuclear \\
\hline D9FE & 9 & Femenino & 3ro primaria & 8 meses & Extensa \\
\hline J10FE & 9 & Femenino & 5to primaria & 1 año & Extensa \\
\hline D11FE & 9 & Femenino & 5to primaria & 1 año & Reconstruida \\
\hline JJ10ME & 10 & Masculino & 5to primaria & 9 meses & Nuclear \\
\hline J10ME & 10 & Masculino & 4to primaria & 15 meses & Extensa \\
\hline Y10ME & 10 & Masculino & 4to primaria & 2 años & Nuclear \\
\hline S52FD & \multicolumn{5}{|c|}{$\begin{array}{l}\text { Mujer, } 52 \text { años de edad. Docente desde hace } 25 \text { años. Lleva un año laborando } \\
\text { en la institución educativa }\end{array}$} \\
\hline P54FD & \multicolumn{5}{|c|}{$\begin{array}{l}\text { Mujer, } 54 \text { años de edad. Docente de educación especial, lleva ejerciendo su } \\
\text { profesión por } 24 \text { años, de los cuales } 12 \text { ha estado en la institución educativa, } \\
\text { se desempeña como profesora de primaria }\end{array}$} \\
\hline S60FP & \multicolumn{5}{|c|}{ Mujer, 60 años. Lleva ejerciendo la docencia por 40 años. Docente de primaria } \\
\hline
\end{tabular}

Fuente: elaboración propia. 


\section{Procedimiento}

El acercamiento al campo se hizo inicialmente por intermedio de una de las docentes de la institución. Una vez socializados los objetivos de la investigación con las directivas del colegio, se invitó a los niños y a los docentes a participar, siempre y cuando tuvieran los criterios de inclusión para vincularse.

Las entrevistas de los niños y las niñas fueron hechas en dupla en la institución educativa. El mural de situaciones se realizó en sesiones grupales y se orientaron los dibujos en tres momentos: la vida en Venezuela, la vida durante las trayectorias de la migración y la vida en Medellín. Se tomó registro de audio, vídeo y fotografías de todo el proceso de recolección de la información, previa autorización de los participantes. El consentimiento informado fue avalado por el comité de ética de la Universidad Católica Luis Amigó.

En el recorrido de la investigación, no se presentó ninguna dificultad con la población seleccionada, fue fácil el acceso a esta y a la hora de realizar las entrevistas hubo buena disposición por parte de los menores. La realización de las entrevistas en duplas permitió que los niños sintieran más confianza, lo cual causó respuestas más espontáneas.

\section{Análisis de los datos}

El análisis de los datos se hizo a partir de las fases propuestas por Martínez Miguélez (2004) en clave al enfoque de interseccionalidad. Se trató de hacer una lectura de las experiencias de los estudiantes venezolanos con características diferenciales como el curso de vida y su condición de migrante en el contexto de una escuela pública en Colombia.

\section{Resultados}

Los resultados fueron agrupados en tres secciones a partir del análisis de las categorías.
En primer lugar, presentamos el proceso de adaptación escolar de los niños a la institución educativa. Posteriormente abordamos los hallazgos en torno al duelo migratorio y, por último, mostramos las formas del acompañamiento docente.

\section{El tránsito escolar: entre la adaptación a los pares y los desafíos curriculares}

La falta de alimentos o el encarecimiento de los mismos, la inseguridad, la imposibilidad para acceder a productos básicos de la canasta familiar son algunas de las causas que ocasionaron la salida de Venezuela en las familias de los participantes. Al indagar por los motivos del viaje a Colombia se destacan los siguientes testimonios:

\footnotetext{
Porque la situación estaba muy fuerte y todo estaba caro, fuerte quiere decir que muy mala, tiran bombas, cohetes y ellos veían eso, acá se sientes más seguros (D9FE, comunicación personal).
}

Porque Maduro es un loco, suben y bajan los precios. Estaba muy mal (A8ME, comunicación personal).

Los niños destacaron en sus dibujos la bandera de Venezuela (imagen 1) como un aspecto significativo dentro de su formación escolar, el cual asocian con sentimientos positivos a la patria. Ahora bien, ellos no solo reconocen las causas de la migración, sino que además relacionan la situación política de Venezuela como un elemento que condicionó la salida y expuso al núcleo familiar a situaciones de riesgos; el Estado se aprecia como un ente que persigue y expulsa a los ciudadanos.

La llegada a la nueva escuela implicó una ruptura abrupta con la trama relacional y escolar construida en su país de origen. Una de las necesidades más imperantes por parte de los estudiantes al incursionar en la nueva escuela fue sentirse aceptado e incluido en 
la dinámica escolar, especialmente ser valorados por sus pares. No obstante, el proceso de adaptación a la nueva dinámica escolar no siempre es sencillo; estuvo mediado por la xenofobia, la distinción de clase y el proceso de aculturación.

Los niños deben, en primer lugar, adaptarse al contexto social, cultural y familiar, pero también sobrellevar el rechazo de los compañeros en la escuela. El uso de calificativos como "venezolanos" y en especial "veneco" tenía como propósito marcar distancia entre los nacionales y los extranjeros. El otro que llega se percibe como amenazante y perturbador de la dinámica escolar, y se le nombra a partir de adjetivos que son escuchados a los adultos y que se usan con la intención de violentar mediante la palabra.

Que los compañeros iban a ser buenos. No todos lo han sido, siempre me molestan todos los niños, menos mis amigos. Me molestan por ser venezolano (Á8ME, comunicación personal).

Yo les digo a los profesores, ellos les dicen que no humillen y hacen caso (D11FE, comunicación personal).

A mí me dicen negra mujinga o veneca porque soy negra y venezolana. Yo me quedo callada, no le digo nada a nadie (D11ME, comunicación personal).

La trama socializadora en el aula de clase de las niñas fue más compleja y sintieron de manera más emocional las burlas de los compañeros. En el caso de los niños, las docentes expresaron que hacían uso de las agresiones físicas para defenderse de los comentarios de los nacionales. Los modelos interseccionales de desventaja social (Cole, 2009) sugieren que las categorías sociales se combinan para dar forma a las experiencias y los resultados de la vida de los individuos en todos los ámbitos. En este caso particular, la condición de migrante per se genera exclusión y rechazo, que se intensifica al ser mujer y afrodescendiente.
La migración opera en algunos contextos como un mecanismo de estratificación que impacta de manera diferencial a los individuos y grupos e influye en el acceso a los determinantes sociales (por ejemplo: trabajo, vivienda segura, derechos, seguridad). Tener el estatus de migrante contribuye a que la desigualdad se incremente y se refuercen los estereotipos negativos que son difundidos constantemente en medios de comunicación, en las interacciones sociales y que permean las aulas de clase.

Los niños locales introyectan los estereotipos de los adultos acerca de los extranjeros que se ponen en evidencia en la interacción escolar. La adecuada mediación por parte de la institución educativa pone límites a las agresiones verbales y facilita que venezolanos y colombianos se integren fácilmente.

Por otro lado, una de las dificultades en la adaptación escolar que relataron los participantes se relaciona con el currículo académico. Los contenidos escolares en las instituciones educativas de Colombia se distancias de las de Venezuela. Así, un niño que en el país de origen estuviera cursando cuarto grado de primaria sería un equivalente en Colombia a segundo o tercero de primaria. Esta distancia curricular afecta la valía de los niños migrantes, les genera inseguridad sobre sus conocimientos y competencias; a lo que se le suman comentarios despectivos por parte de los estudiantes nacionales que intensifican las conductas de acoso escolar.

Esta brecha académica entre estudiantes migrantes y colombianos se refuerza cuando las instituciones educativas, en particular las públicas, no hacen un acompañamiento cercano al proceso de enseñanza-aprendizaje a los estudiantes, en parte por la cantidad de niños en el aula, pero también porque no se cuentan con las competencias técnicas y pedagógicas necesarias para integración. 


\section{Duelo migratorio}

El duelo migratorio se puede considerar muy complejo porque abarca pérdidas en todos los ámbitos, no solo en el cultural, también en lo social, educativo, familiar y personal a causa de una sola situación: la migración.

El duelo migratorio es complejo, difícil de llevar y más cuando las situaciones personales o sociales de los migrantes son problemáticas. El migrante no vive un solo duelo, sino que la experiencia de pérdida puede ser más amplia. En el estudio, los tipos de duelos que se evidenciaron con mayor intensidad en los niños fueron el duelo a la familia y amigos, a la tierra y el contacto con el grupo étnico.

Las decisiones respecto a la migración no suelen ser consultadas con los niños y tampoco mencionadas con antelación. Se toman de un momento a otro imposibilitando una despedida con el círculo más cercano de familiares o amigos. Esto dificulta que se elabore la separación con las personas significativas que se quedan en Venezuela.

La configuración de la familia tradicional cambia con la migración y toma el carácter de familia transnacional. La movilidad internacional de alguno de los miembros contribuye a dispersar tanto los hogares como los lazos familiares, "se cuestionan concepciones tradicionales asociadas a la presencialidad física, la relación cara a cara y la corresidencia, en tanto sus miembros establecen relaciones y vínculos desde la distancia física desplegando cierta creatividad en las prácticas familiares" (Zapata Martínez, 2021, p. 77). Es precisamente la familia lo que más extrañan los niños, según sus relatos:

Nos vinimos porque hacía mucha falta la comida y por eso nos íbamos a venir. Yo no me quería ir. Allá dejé a mi abuelo, a mi tío, amigos, mi escuela, mi vida.

Dejar a mi familia, mis abuelos, mis tías, mis primos. No me pude siquiera despedir de ellos (A8ME, comunicación personal).
Ante la movilidad a un nuevo país la vida social del niño se transforma, perdiendo autonomía. La posibilidad de compartir con los otros familiares y con sus amigos se encuentra coartada por la lejanía inevitable. Como elementos centrales de la percepción subjetiva del niño están el fin de la continuidad y de su identidad, que debe reconstruirse en un nuevo país.

Berry (2002) conceptualiza la aculturación como el proceso por medio el cual los sujetos cambian su propia cultura, como resultado del contacto con otra cultura. En el caso de los niños, y considerando su momento vital, convertirse en uno más puede contribuir a una mayor aceptación en el país receptor.

La prosodia, el acento y el sentido diferente de las palabras que se encuentran en los modismos propios de un país obligan al migrante a irse aculturizando a la lengua del país de llegada. Ahora bien, hablar el mismo idioma, en este caso el español, permite que no haya una barrea idiomática que obstaculice la relación del migrante con los nacionales.

La tierra, el paisaje, los colores, los olores y la humedad son algunos elementos que generan una carga afectiva en las personas y que a menudo se suelen desconocer (Atxotegui, 2000). Los migrantes cuyo vínculo a la tierra es fuerte viven intensamente los cambios de paisaje. Uno de los hallazgos fue que el duelo por la tierra se pone en evidencia al nombrar los espacios físicos que se extrañan o tenían un significado especial para las personas. Los niños relataban que añoraban los espacios verdes de Venezuela, los cuales son distantes en su localidad y en su actual colegio. Como se aprecia en la imagen 1, este duelo en particular se hizo visible en las representaciones del espacio escolar: la ilustración de la escuela de origen era recreada con colores vivos, con mayores detalles que la escuela actual. 


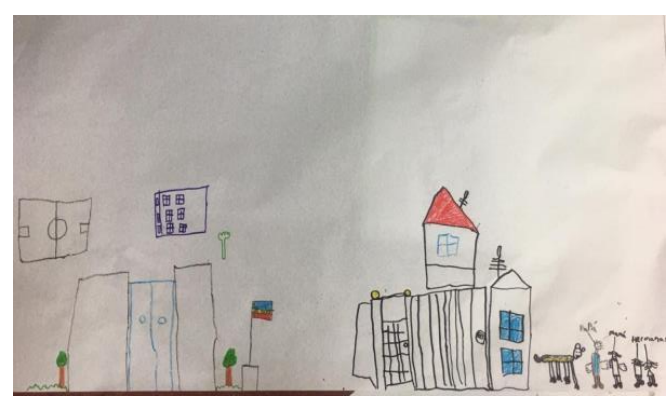

Escuela en Venezuela

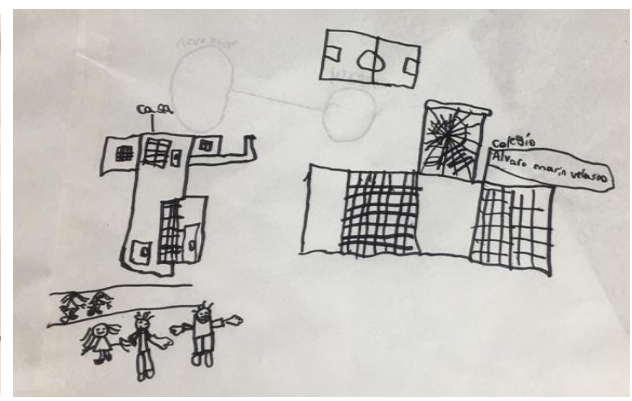

Escuela en Colombia

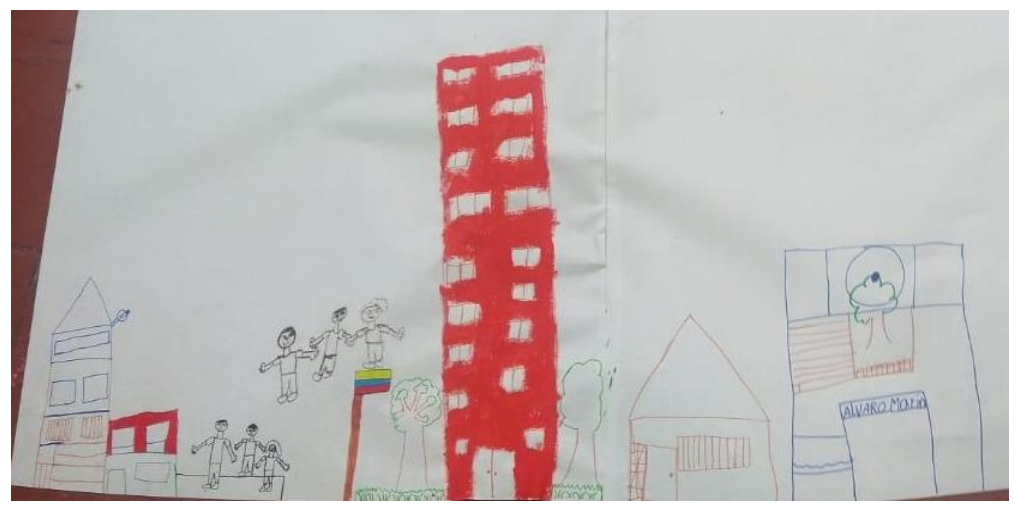

Escuela en Venezuela

Escuela en Colombia

Imagen 1. La escuela en Venezuela y Colombia.

Fuente: elaboración de los participantes

El contraste plasmado en los dibujos sobre el espacio escolar en Venezuela y Colombia deja en evidencia varios aspectos. El primero de ellos es la disparidad en las características espaciales de la escuela que se detallan en mayor tamaño y colores en el país de origen, frente a un espacio más reducido y sombrío como es la representación de la escuela actual. En segundo lugar, junto con la representación espacial se puede asociar la disparidad en las condiciones económicas actuales, más reducidas que las que vivieron antes de la crisis en el vecino país. Finalmente, los dibujos también proyectan parte de la vivencia escolar que, como se mencionó anteriormente, se caracteriza por actos de discriminación y xenofobia.
Para los niños el ser aceptado por el grupo resulta fundamental en la construcción de una autovaloración positiva. Ellos comparan sus habilidades y logros con relación a los otros, buscando al mismo tiempo la aprobación de los pares. Esto permite que vayan adquiriendo una perspectiva de sí mismos más integrada y compleja, afianzando un sentido de identidad. Conforme a esto, el duelo por grupo étnico se hace presente cuando los niños venezolanos son objetos de burla por su nacionalidad.

A mí sí me siguen diciendo veneco o venezolano y no me gusta que me digan así, me siento mal porque no me gusta que me digan así sólo porque seamos venezolanos, la profe no deja que nos digan eso (S8ME, comunicación personal). 
Atxotegui (2000) enuncia que uno de los elementos de la identidad se asocia a la conciencia de un "nosotros" ante un "ellos". Es un sentimiento de pertenencia a un grupo o nación externa. El duelo migratorio puede generar desarraigo, categoría percibida por las docentes en los estudiantes venezolanos:

Es muy extremo, unos (niños venezolanos) son excelentes y otros son muy quedados. Es simplemente la situación de ellos, ellos viven hacinados, no se alimentan bien. Son muchas cosas, ellos vienen desarraigados, necesitan terapia, apoyo, entonces yo pienso que más bien lo que les afecta es ese desarraigo (S60FD, comunicación personal).

El relato de la docente expone las situaciones de vulnerabilidad de los niños migrantes y la necesidad de atención psicológica para dar trámite a las trayectorias en su curso de vida. El desarraigo se relaciona con un sentimiento de no-identificación, falta de interés o lazo con el entorno en el que está inscrito un sujeto, el cual siente añoranza por algo que no se tiene o que se perdió en el transcurso de la vida (Rodríguez Pérez, 2012). Aunque las docentes asocian la experiencia de los niños migrantes al desarraigo, es apresurado tal afirmación., dado el tiempo de permanencia en el país. Se considera que la experiencia está atravesada por un proceso de duelo migratorio muy propio en estas circunstancias. De la evolución de este duelo se podría revisar si son capaces de crear o no arraigo en el país.

\section{El papel de la escuela}

Las entrevistas con las docentes evidenciaron los esfuerzos de la institución educativa para nivelar a los estudiantes migrantes y así poderlos adaptar académicamente y garantizar el nivel académico colombiano. Es importante mencionar que la adaptación escolar en el ámbito académico no solo va a depender de los docentes y la institución educativa, los padres de familia juegan un papel importante en el respectivo acompañamiento que se debe hacer desde el hogar.

En este proceso también se presentan factores que dificultan la adaptación de los niños migrantes tales como desconfianza hacia la institución educativa y los docentes.

La mayor dificultad ha sido con nosotros los profesores, el acercamiento, porque ellos se sienten rechazados o traen las consecuencias de su país y dicen que no los queremos, que no los aceptamos pero no es eso, porque de alguna manera ellos se ven sacados de allá y no de la mejor manera, entonces aquí se ven como arrimados, vine aquí porque me tocó pero lo otro es que cuando están interactuando con los demás van adquiriendo confianza, simpatizan y se vuelven hasta buenos compañeros y hacen trabajos cooperativos entre ellos (P54FD, comunicación personal)

El espacio escolar fue percibido como un lugar de estancia, en el que las condiciones materiales y de implementación tienen una apreciación positiva, aún con sus limitantes, al igual que el trato que reciben por parte de los docentes. En los relatos, los niños resaltan la defensa y los límites que el cuerpo docente instauraba hacía los comentarios recibidos por los compañeros.

Algunos de los agentes que facilitan la adaptación son el acompañamiento psicológico a los estudiantes y la debida mediación escolar de los docentes cuando se presentan casos de acoso. También se encontró que, si bien en Venezuela los niños tenían espacios más grandes y con zonas verdes en la institución, disfrutan mucho de los espacios físicos que la institución actual les brinda: cancha, biblioteca, sala de computadores, tienda y demás, donde pueden jugar, llevar a cabo las actividades de ocio y tener una alimentación básica que en algunos hogares es limitada.

La inclusión de los niños en el sistema educativo no garantiza la superación de condiciones estructurales, pero sí se presen- 
ta como un factor protector para ellos. Se destaca, así, que las instituciones educativas pueden ser actores que faciliten o no los procesos de adaptación de los niños migrantes. La adaptación debe involucrar un proceso de inclusión que va desde lo académico a lo social. De igual manera, se deben mediar oportunamente las situaciones de bullying y xenofobia.

\section{Discusión}

El propósito de la investigación fue analizar la experiencia de los niños venezolanos en las aulas de clase en la ciudad de Medellín, específicamente en la Institución Educativa Álvaro Marín Velasco.

La experiencia en las aulas de clase estará supeditada en primer lugar a los recursos personales y familiares con los que llegan los niños. Como lo señala Kaluf (2009), al incorporarse al sistema educativo del país de llegada, los niños migrantes pueden presentar mayores dificultades en el proceso de enseñanza-aprendizaje.

En la adaptación escolar influyen muchos factores, entre ellos las características étnicas, económicas y de género que facilitan o no sentirse aceptados y acogidos por sus pares y docentes. La acogida y la disposición de la institución educativa, en especial de los docentes que acompañen el proceso de enseñanza-aprendizaje, son claves para la inclusión de los menores en la dinámica escolar y tendrá efectos en el rendimiento académico y en los vínculos que se gesten con pares. Para Inzunza Gillibrand y Videla Contreras (2014), la visión acerca de los profesores es mayoritariamente negativa, algunos niños refieren que el trato es diferente con relación a los profesores del país de origen. Esto es totalmente opuesto a lo que encontramos en la investigación realizada, pues los niños se han sentido acogidos y aceptados por sus docentes.
Los pares tienen una alta influencia en la constitución de la autoestima del sujeto. Una mala recepción por parte del grupo podría comprenderse como la posibilidad de una desorganización en la configuración de una nueva identidad, ahora mediada por la migración. La conducta de discriminación y rechazo o las agresiones físicas tienen un impacto mucho mayor en las niñas migrantes y en su valoración personal. En el caso de los niños, el uso de la violencia se convierte en una defensa.

Los resultados visibilizaron la exposición de los niños venezolanos a actos de xenofobia o bullying por parte de sus pares a causa de su nacionalidad. Estos actos de discriminación se han puesto en evidencia en investigaciones similares. Inzunza Gillibrand y Videla Contreras (2014) destacan que, en cuanto a la recepción por parte de los compañeros del colegio, gran parte de las niñas y niños manifiesta haber sido víctima de molestias como, por ejemplo, burlas y malas palabras. Por su parte, Pavez (2012a) coincide en que en los estudiantes extranjeros recaen las imágenes estereotipadas que suelen hacerse a los colectivos de migrantes, en este caso la imagen de un otro que llega a usurpar y quitar derechos a los nacionales.

Esta investigación dio cuenta de la importancia de la complementación de diversos factores para llevar a cabo una adaptación escolar adecuada. Es relevante resaltar que la socialización con pares es el principal aliado a la hora de establecer relaciones seguras en el entorno con los docentes, el espacio físico y la nueva forma de aprendizaje. De igual manera, la comprensión de los diversos duelos que involucran la migración se deben leer como un estado normal ante la pérdida, pero es importante un acompañamiento psicológico para darle trámite.

Aunque la legislación colombiana ha mostrado importantes avances en políticas que han logrado garantizar la protección inte- 
gral de los niños migrantes, aún persiste el reto de la promulgación de leyes que comprendan la realidad de los flujos migratorios, sobre todo en niños (López Villamil et al., 2018).

Para finalizar, es importante destacar las limitaciones de la investigación. En primer lugar, el número reducido de participantes y la no inclusión en la muestra de la percepción de estudiantes colombianos y de los cuidadores de los participantes. Ampliar estos dos elementos podría extender la comprensión del fenómeno estudiado. En segundo lugar, investigaciones longitudinales podrían mostrar la evolución de las relaciones entre los niños nacionales y los venezolanos, y la evolución de los duelos migratorios.

Las movilizaciones humanas, especialmente las que son forzadas, han puesto en evidencia una alteridad mediada por la vulnerabilidad personal y social; en el caso de los niños, aunque se hace más evidente, ha sido poco leída y comprendida. Es importante reivindicar en los estudios la experiencia de los niños en la migración, fomentar estudios futuros sobre las disparidades de la formación y la socialización infantil con incidencia en la etnia, el género, la raza y la cultura.

\section{Referencias}

Achotegui, J. (2010). Cómo evaluar el estrés y el duelo migratorio. El mundo de la Mente.

Atxotegui, J. (2000). Los duelos de la migración: una aproximación psicopatológica y psicosocial. En E. Perdiguero Gil y J. M. Comelles (Coord.), Medicina y cultura: Estudios entre la Antropología y la Medicina (pp. 83-100). Bellaterra.

Bauman, Z. (2013). Sobre la educación en un mundo líquido. Ediciones Paidós.

Bauman, Z. (2016). Extraños llamando a la puerta. Ediciones Paidós.

Berger, P. L., \& Luckmann, T.(1968). La construcción social de la realidad. Amorrortu.
Berry, J. W. (2002). A Psychology of Immigration. Journal of Social Issues, 57(3), 375-387. https://doi.org/10.1111/0022-4537.00231

Blanco, M. (2011). El enfoque del curso de vida: orígenes y desarrollo. Revista Latinoamericana de Población, 5(8), 5-31. https://doi. org/10.31406/relap2011.v5.i1.n8.1

Castillo Crasto, T. y Reguant Álvarez, M. (2017). Percepciones sobre la migración venezolana: causas, España como destino, expectativas de retorno. Migraciones. Revista del Instituto Universitario de Estudios sobre Migraciones, (41), 133-163. https://doi.org/10.14422/ mig.i41.y2017.006

Cerón, L., Pérez Alvarado, M. y Poblete, R. (2017). Percepciones Docentes en torno a la Presencia de Niños y Niñas Migrantes en Escuelas de Santiago: Retos y Desafíos para la Inclusión. Revista latinoamericana de educación inclusiva, 11(2), 233-246. http://dx.doi.org/10.4067/ S0718-73782017000200015

Chiu, M. L., Feldman, S. S. y Rosenthal, D. A. (1992). The influence of immigration on parental behavior and adolescent distress in Chinese families residing in two western nations. Journal of Research on Adolescence, 2(3), 205-239. https://www.tandfonline. com/doi/abs/10.1207/s15327795jra0203_2

Cole, E. R. (2009). Intersectionality and research in psychology. American Psychologist, 64(3), 170-180. https://doi.org/10.1037/a0014564

Inzunza Gillibrand, K. M. y Videla Contreras, V. (2014). Manifestación del duelo migratorio en niños y niñas inmigrantes peruanos residentes en Santiago de Chile [tesina de grado, Universidad Academia de Humanismo Cristiano]. Repositorio Institucional UAHC.

Jiménez, F., Aguilera Valdivia, M., Valdés Morales, R. y Hernández Yáñez, M. (2017). Migración y escuela: Análisis documental en torno a la incorporación de inmigrantes al sistema educativo chileno. Psicoperspectivas, 16(1), 105-116. https://scielo.conicyt.cl/pdf/ psicop/v16n1/art10.pdf

Joiko, S. y Vásquez, A. (2016). Acceso y elección escolar de familias migrantes en Chile: No 
tuve problemas porque la escuela es abierta, porque acepta muchas nacionalidades. Calidad en la Educación, (45), 132-173. http://dx.doi. org/10.4067/S0718-45652016000200005

Kaluf, M. (2009). Niños inmigrantes peruanos en la escuela chilena. [Tesis de Magister, Universidad de Chile]. http://repositorio. uchile.cl/bitstream/handle/2250/106235/ Ninos-inmigrantes-peruanos.pdf? sequence $=3$

Kelly, U. A. (2011). Theories of intimate partner violence: From blaming the victim to acting against injustice: Intersectionality as an analytic framework. Advances in Nursing Science, 34(3), E29-E51. doi: 10.1097/ ANS.0b013e3182272388

López Castro, G. (1999). La educación en la experiencia migratoria de niños migrantes. En G. Mummert (Ed.), Fronteras Fragmentadas (pp. 359-374). El Colegio de MichoacánCIDEM.

López Villamil, S., Rodríguez Lizarralde, C., Aristizábal González, L. D. y Barriga Durán, L. C. (2018). Infancias migrantes en Colombia: retos del derecho a la educación. Hojas y Hablas, (16), 10-26. https://doi. org/10.29151/hojasyhablas.n16a1

Martínez Miguélez, M. (2004). Ciencia y arte en la metodología cualitativa. Trillas.

Matus, C. y Rojas, C. (2015). Normalidad y diferencia en nuestras escuelas: a propósito de la Ley de Inclusión Escolar. Docencia, 56, 47-56. https://www.revistadocencia.cl/web/ images/ediciones/Docencia_56.pdf

Ministerio de Relaciones Exteriores de Colombia. (2021, 29 de enero). Distribución de venezolanos en Colombia 2020. Migración Colombia. https://cutt.ly/OkLTJeS

Millán Otero, K. L., Duran Palacio, N. M. y Castaño Cano, L. M. (2021). Aproximaciones al Duelo Migratorio de los Venezolanos Residentes en la Ciudad de Medellín, Colombia: Un Estudio Cualitativo. The Qualitative Report, 26(6), 1830-1845. https://doi.org/10.46743/2160$3715 / 2021.4814$

Organización Internacional para las Migraciones. (2006). Glosario sobre migración. Derecho
Internacional sobre Migración, $\mathrm{N}^{\circ}$ 7. http:// publications.iom.int/system/files/pdf/iml_7 sp.pdf

Ortiz Giraldo, A. (2012). Caracterización Comuna 3 Manrique De La Ciudad De Medellín. Kavilando. https://www.kavilando. org/index.php/2013-10-13-20-05-51/ informes/2324-caracterizacion-comuna-3manrique-de-la-ciudad-de-medellin

Pavez Soto, I. (2012a). Inmigración y racismo: experiencias de la niñez peruana en Santiago de Chile. Si somos americanos. Revista de Estudios Transfronterizos, 12(1), 75-99. http://dx.doi.org/10.4067/S071909482012000100004

Pavez Soto, I. (2012b). Migración infantil: rupturas generacionales y de género. Las niñas peruanas en Barcelona y Santiago de Chile. Universitat Autònoma de Barcelona.

Restrepo Pineda, J. E. y Jaramillo Jaramillo, J. (2020). Percepción de líderes sociales y representantes de organizaciones públicas y privadas sobre la migración y los inmigrantes venezolanos en el municipio de Maicao (La Guajira, Colombia). Migraciones. Revista del Instituto Universitario de Estudios sobre Migraciones, (49), 119-145. https://doi. org/10.14422/mig.i49.y2020.005

Rodríguez Pérez, M. A. (2012). El desarraigo y la crisis educativa. Revista Científica de FAREMEstelí, (2). https://rcientificaesteli.unan.edu. ni/index.php/RCientifica/article/view/468

Sánchez Mimbela, V. (2017). El duelo migratorio en estudiantes de primaria y su culturización. En R. I. Roa Rivera, E. Santillán Anguiano, D. Islas Cervantes y Y. A. López López (Aut.), Migración, Educación y Sociedad: Visiones y experiencias desde la frontera (pp. 129-140). Editorial Redipe.

Stake, R. E. (1999). Investigación con estudio de casos. Ediciones Morata.

Suárez-Orozco, C. y Suárez-Orozco, M. M. (2003). La infancia de la inmigración. Ediciones Morata.

Taylor, S. y Bogdan, R. C. (1989). Introducción a los métodos cualitativos de investigación. Paidós. 
Vargas Valle, E. D. y Camacho Rojas, E. (2015). ¿Cambiarse de escuela? Inasistencia y rezago escolar de los niños de migración reciente de Estados Unidos a México. Norteamérica, Revista Académica del CISAN-UNAM, 10(2), 157-186. https://doi.org/10.20999/nam.2015.b006

Vera Noriega, J. Á. (2009). Depresión, ansiedad y estrés en niños y niñas jornaleros agrícolas migrantes. Psico, Porto Alegre, PUCRS, 40(3), 337-345. https://n9.cl/loy1
Zapata Martínez. A. (2021). El hogar en contextos transnacionales: una reflexión desde la migración de madres/padres colombianos a Santiago de Chile. Antípoda. Revista de Antropologíay Arqueología, (3), 75-96. https:// doi.org/10.7440/antipoda43.2021.04

Zimmerman C., Kiss L. y Hossain M. (2011). Migration and health: A framework for 21st century policy-making. PLoS Medicine. 8(5), 1001-1034. https://doi.org/10.1371/journal. pmed.1001034 